\title{
Incidence, risk factors and consequences of preterm birth - findings from a multi- centric observational study for 14 months in Nepal
}

Abhishek Gurung ${ }^{1}$ D, Johan Wrammert ${ }^{2} \mathbb{D}$, Avinash K. Sunny ${ }^{1}$ (D) Rejina Gurung ${ }^{1} \mathbb{D}$, Netra Rana ${ }^{3}$, Yuba Nidhi Basaula ${ }^{4}$, Prajwal Paudel ${ }^{5}$, Amrit Pokhrel ${ }^{6}$ and Ashish $\mathrm{KC}^{2^{*}}$ (i)

\begin{abstract}
Background: Preterm birth is a worldwide epidemic and a leading cause of neonatal mortality. In this study, we aimed to evaluate the incidence, risk factors and consequences of preterm birth in Nepal.

Methods: This was an observational study conducted in 12 public hospitals of Nepal. All the babies born during the study period were included in the study. Babies born $<37$ weeks of gestation were classified as preterm births. For the association and outcomes for preterm birth, univariate followed by multiple regression analysis was conducted.

Results: The incidence of preterm was found to be 93 per 1000 live births. Mothers aged less than 20 years (aOR $1.26 ; 1.15-1.39)$ had a high risk for preterm birth. Similarly, education of the mother was a significant predictor for preterm birth: illiterate mothers (aOR 1.41; 1.22-1.64), literate mothers (aOR 1.21; 1.08-1.35) and mothers having basic level of education (aOR 1.17; 1.07-1.27). Socio-demographic factors such as smoking (aOR 1.13; 1.01-1.26), use of polluted fuel (aOR 1.26; 1.17-1.35) and sex of baby (aOR 1.18; 1.11-1.26); obstetric factors such as nulliparity (aOR $1.33 ; 1.20-1.48$ ), multiple delivery (aOR 6.63; 5.16-8.52), severe anemia during pregnancy (aOR 3.27; $2.21-4.84$ ), antenatal visit during second trimester (aOR 1.13; 1.05-1.22) and third trimester (aOR 1.24; 1.12-1.38), < 4 antenatal visits during pregnancy (aOR 1.49; 1.38-1.61) were found to be significant risk factors of preterm birth. Preterm has a risk for pre-discharge mortality (10.60; 9.28-12.10).
\end{abstract}

Conclusion: In this study, we found high incidence of preterm birth. Various socio-demographic, obstetric and neonatal risk factors were associated with preterm birth. Risk factor modifications and timely interventions will help in the reduction of preterm births and associated mortalities.

Trial registration: ISRCTN30829654.

Keywords: Preterm, Risk factors, Stillbirth, Neonatal mortality, Nepal

\footnotetext{
*Correspondence: aaashis@yahoo.com

${ }^{2}$ Department of Women's and Children's Health, Uppsala University, 75237 Uppsala, Sweden

Full list of author information is available at the end of the article
}

(C) The Author(s). 2020 Open Access This article is licensed under a Creative Commons Attribution 4.0 International License, which permits use, sharing, adaptation, distribution and reproduction in any medium or format, as long as you give appropriate credit to the original author(s) and the source, provide a link to the Creative Commons licence, and indicate if changes were made. The images or other third party material in this article are included in the article's Creative Commons licence, unless indicated otherwise in a credit line to the material. If material is not included in the article's Creative Commons licence and your intended use is not permitted by statutory regulation or exceeds the permitted use, you will need to obtain permission directly from the copyright holder. To view a copy of this licence, visit http://creativecommons.org/licenses/by/4.0/ The Creative Commons Public Domain Dedication waiver (http://creativecommons.org/publicdomain/zero/1.0/) applies to the data made available in this article, unless otherwise stated in a credit line to the data. 


\section{Background}

Preterm birth ( $<37$ weeks of gestation) is one of the leading causes of neonatal morbidity and mortality and a significant public health burden $[1,2]$. Every year, there are 15 million (11.1\%) preterm births of all births worldwide, and $13.3 \%$ of these births occur in South Asia alone [1]. In Nepal, it is reported that around 81,000 newborns are born preterm every year [3]. A study conducted by Lee and colleagues in 2010 reported 14\% preterm births [4]. Despite the increase in burden of preterm births worldwide, the data available from developing countries like Nepal is very scarce [5]. In order to achieve the Sustainable Development Goal 3 target of reaching the neonatal mortality rate to 12 per 1000 live birth by 2030 , it is critical to address the burden of preterm births [6].

Babies born preterm have a higher risk of dying as reported from a multi-country study conducted in low- and middle-income countries (LMICs) [7]. The greater risk of dying has been mostly associated with neonatal infections [8]. In comparison to term infants, they are more prone to short and long-term neurocognitive and motor impairments together with increased risk of malnutrition, chronic diseases and early deaths $[9,10]$.

Several factors have been identified as risks for preterm birth. Socio-demographic factors such as ethnicity, older age of mothers and smoking have been reported as risk factors for preterm birth [11, 12]. Low education levels of mothers have also been documented as risk factors for preterm birth by many studies [13-15]. Primiparity has been linked as an obstetric risk factor for preterm birth [16]. Further, poor access to antenatal care services during pregnancy leads to poor pregnancy outcomes like preterm births as demonstrated by a hospital-based study in Nepal [17].

Studies have also been conducted showing providerinitiated interventions like induction of labor and caesarean section are attributable to preterm births [5, 18, 19]. However, very few studies have been conducted assessing the risk factors with preterm births in the context of Nepal. In order to develop suitable interventions for preventing morbidities and mortalities associated with preterm, it is essential to understand the underlying risk factors linked with preterm births and manage them [20]. This study is aimed to address this evidence gap through evaluating the incidence, risk factors and consequences related to preterm births in Nepal.

\section{Method}

Aim

The study aimed to evaluate the incidence, risk factors and consequences of preterm birth in Nepal.

\section{Study design and setting}

This observational study is nested within the Helping Babies Breathe Quality Improvement Project in 12 hospitals of Nepal [21]. These hospitals are governmentfunded providing referral level obstetric and neonatal care services. The hospitals were selected based on having an annual delivery of $>1000$ per year and which were operated by the government. The hospitals were selected randomly for the study, after which the hospitals were divided into four wedges, with each wedge having a large-sized (>5000 deliveries per year), midsized (3-5000 deliveries per year) and small-sized hospitals (> 1000 deliveries per year) [21]. This study was conducted for a period of 14 months from 1 July 2017 to 29 August 2018.

\section{Study participants \\ Inclusion criteria}

All babies who were delivered in the selected hospitals were included for this study.

\section{Exclusion criteria}

The mothers of the newborn babies who did not provide consent were excluded.

\section{Data collection and management}

A data surveillance system was established in all the hospitals to collect data on babies and their mothers. It included data collectors based in each of the hospitals with data coordinators, who collected data on all pregnant women from admission until discharge through extraction and exit interviews. All pregnant women who were admitted to the hospital for delivery and who consented to data collection were given unique identification (ID) numbers. Data was collected during labor, delivery and post-partum period. Study IDs were allocated for each hospital, which were assigned by the data collectors for each individual pregnant woman. For obstetric information, data were extracted from patient file and Maternity Register using a data retrieval form (Additional file 1). For sociodemographic variables, data were collected through semi-structured interviews with mothers before discharge (Additional file 2).

The forms that were completed were then assessed by the data coordinator at the hospital for completeness and those completed were indexed. The data entry and management team then sorted and indexed the forms and reassessed for completeness. The data were entered and cleaned in Census and Survey Processing System (CSPro). The cleaned data were exported into Statistical Package for the Social Sciences (SPSS) for further data analysis. 
Variables

\section{Outcome variable}

Preterm births - Babies born before 37 weeks of gestation.

Pre-discharge mortality - The death of newborn before discharge.

\section{Demographic variables}

Maternal age, ethnicity, education, smoking history and sex of the baby were included.

\section{Antenatal variables}

Antenatal care (ANC) visit, time of ANC visit and severe anemia during pregnancy were included.

\section{Intrapartum variables}

Parity, induction of labor, mode of delivery, multiple deliveries, major malformation and were included.

\section{Statistical analysis}

The incidence of preterm births was calculated. For socio-demographic and obstetric characteristics, binary logistics regression was performed to analyze the level of association with preterm births. $P$-value of $<0.05$ was considered to be significant. Missing values were excluded from the analysis. Multivariable regression analysis was done for variables that were significant in univariate analysis.

\section{Results}

A total of 63,099 women were admitted and 60,742 deliveries were conducted during the study period. Among the deliveries, 54,778 were term babies while 5964 babies were born preterm (Fig. 1). The incidence of preterm births was found to be 98 per 1000 total births and 93 per 1000 live births (Fig. 2).

In univariate analysis, socio-demographic characteristic such as age of mother, education level, smoking

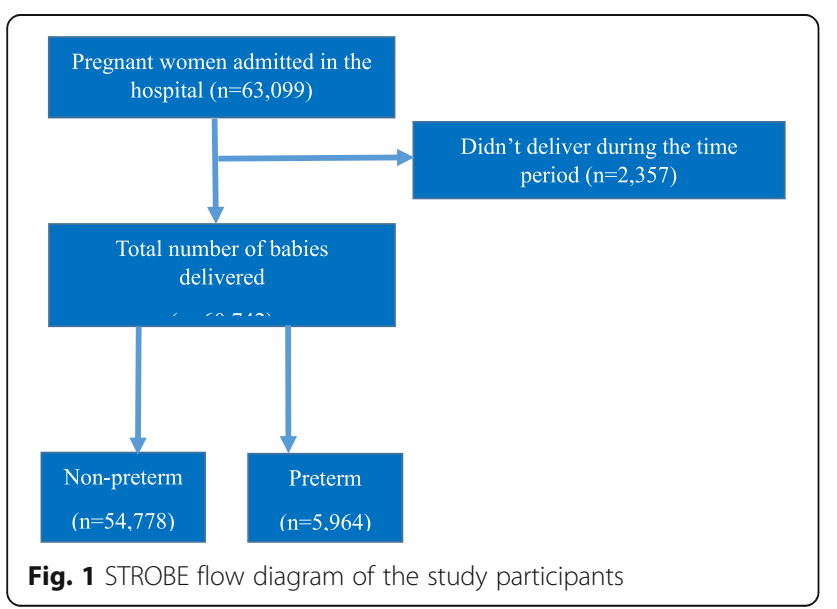

history and type of fuel all showed significant association $(p<0.001)$ with preterm births. Similarly, obstetric characteristics such as multiple delivery, primiparity, time of first ANC visit, frequency of ANC visits, major malformation and severe anemia during pregnancy were found to be significantly associated with preterm births. Female babies were significantly associated with preterm births (Table 1).

Half the total pre-discharge mortalities (50.1\%) were due to preterm births and its complications. Similarly, preterm births had 11-times more risk of pre-discharge mortality (OR 10.60; 9.28-12.10) (Table 1).

The significant variables in univariate were taken for multivariable regression analysis. In comparison to mothers aged 20-35 years, the risk of preterm birth was almost 1.3 times higher (aOR 1.26; 1.15-1.39) when compared to mothers less than 20 years of age. For mothers above 35 years, the risk was 1.2 times higher (aOR 1.20; 0.98-1.47), however the association was found not significant. In comparison to mothers with secondary and higher education level, the risk of preterm births for illiterate mothers was 40\% higher (aOR 1.41; $1.22-1.64$ ), for literate mothers was $20 \%$ higher (aOR $1.21 ; 1.08-1.35)$ and mothers having basic level of education was 20\%higher (aOR 1.17; 1.07-1.27). Similarly, the risk of preterm births among nulliparous mothers was $33 \%$ higher (aOR $1.33 ; 1.20-1.48$ ) compared to multiparous mothers. Time for ANC visits was significantly associated with preterm births with those mothers going for ANC visits in the second trimester was 13\% higher (aOR 1.13; 1.05-1.22) than those who went in the first trimester. The risk of preterm birth was $13 \%$ higher (aOR 1.13; 1.01-1.26) for mothers who had a history of smoking. Further, polluted fuel (aOR 1.26; 1.17-1.35), multiple deliveries (aOR 6.63; 5.16-8.52) and severe anemia during pregnancy (aOR $3.27 ; 2.21-4.84$ ) were also significantly associated with preterm births. Female babies were at 1.18 times higher risk of being born preterm compared to males (aOR 1.18; 1.11-1.26) (Table 2).

\section{Discussion}

The study describes the incidence, risk factors and consequences associated with preterm births based on data available from 12 public hospitals across Nepal. The incidence of preterm births was found to be $9.8 \%$ among total births while it was $9.3 \%$ among live births. In a systematic review conducted with data available from 107 countries, the global preterm birth rate was reported at $10.6 \%$ [22] and a systematic analysis based on data available from 184 countries reported an estimated preterm births of $11.1 \%$ [1]. Studies conducted in the United States (9.62\%) [23] and Australia (8.6\%) [11] have also reported similar estimates. A previous study conducted 


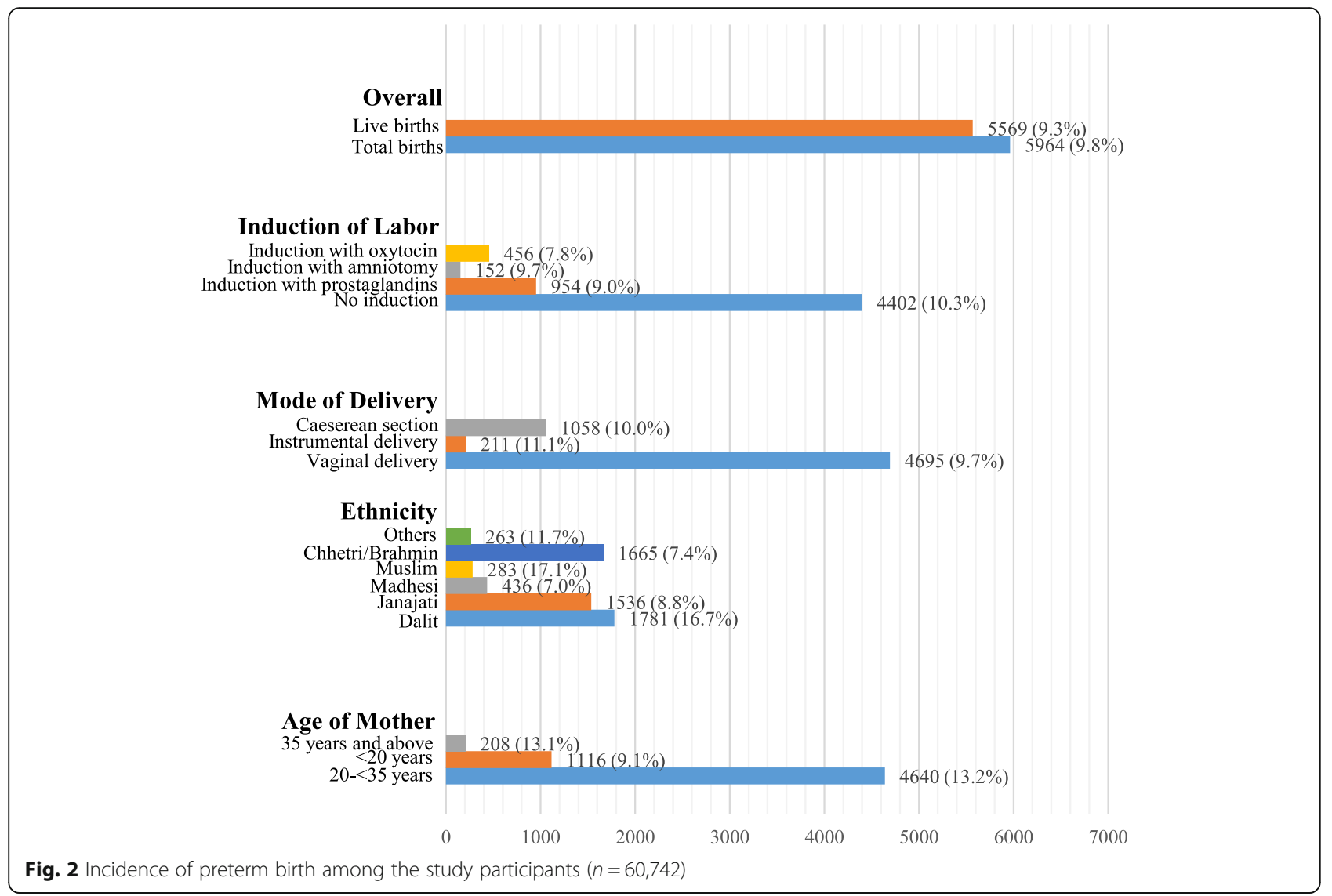

in a tertiary hospital in Nepal reported at incidence of $8.1 \%$ for preterm births [24]. These findings suggest that Nepal's preterm birth rate is in line with developed countries, suggesting an improvement over the national and global estimates.

This study looked at some of the potential risk factors for preterm births. The risk of preterm births was higher among mothers younger than 20 years. Several other studies have also reported linking both younger and older maternal age with preterm births [11, 25-30]. However, a study conducted in Bangladesh found women aged $<20$ years to be protective for preterm, contrary to our findings [20]. Our study did not find any significant association with mothers aged 35 years and above.

The risk of preterm births was also higher among mothers with education lower than secondary level. Other studies have also shown similar associations related to lower education levels [14, 16, 20, 31]. This suggests that better educational status of mothers has a protective effect on birth outcomes. Further, mothers with a history of smoking had higher risk for preterm births. Other studies have also shown similar associations for preterm births [11, 32-34]. The risk of preterm was also higher for mothers who did not use clean fuel.
A recent study conducted in China showed no significant association with the type of fuel used [35]. However, another study conducted in East India looking at the impact of the fuels in pregnancy outcomes showed a significant association for preterm births [36]. The variations could be due to the difference in sample sizes.

Our study showed that the risk of preterm was higher among nulliparous mothers. The findings are supported by previous studies [37, 38]. Babies born to mothers who seek ANC visits during second and third trimesters also had a higher risk of being preterm. Other studies have shown that seeking ANC visits later in pregnancies can increase the risks of preterm births [25, 27, 39]. Our study found that women who sought $<4$ ANC visits during pregnancy were at higher risk of preterm birth. A study conducted in rural Gambia also showed higher risk though the findings were not significant [40]. Further, another study conducted by a Belgian team also found no substantial correlation between number of ANC visits and preterm birth but rather on the content and timing of care during pregnancy [39]. ANC visits should focus on improved screening of at-risk pregnant women together with the ability to treat and manage infections and provide dietary support and counseling services and further research is needed [41]. 
Table 1 Socio-demographic, obstetric and neonatal characteristics of preterm and non-preterm babies

\begin{tabular}{|c|c|c|c|c|c|}
\hline Variables & $\begin{array}{l}\text { Preterm } \\
(\boldsymbol{n}=5964)\end{array}$ & $\begin{array}{l}\text { Non-Preterm } \\
(\boldsymbol{n}=54,778)\end{array}$ & $\begin{array}{l}\text { Total } \\
(\boldsymbol{n}=60,742)\end{array}$ & $\boldsymbol{p}$-value & $\begin{array}{l}\text { OR } \\
(95 \% \mathrm{Cl})\end{array}$ \\
\hline Age of mother & $23.53 \pm 4.7$ & $23.96 \pm 4.33$ & & & \\
\hline $20-<35$ years & $4640(77.8 \%)$ & $46,077(84.1 \%)$ & $50,717(83.5 \%)$ & $<0.001$ & Ref \\
\hline$<20$ years & $1116(18.7 \%)$ & $7322(13.4 \%)$ & $8438(13.9 \%)$ & $<0.001$ & $1.51(1.41-1.62)$ \\
\hline$>35$ years & $208(3.5 \%)$ & $1379(2.5 \%)$ & $1587(2.6 \%)$ & $<0.001$ & $1.50(1.29-1.74)$ \\
\hline \multicolumn{6}{|c|}{ Level of education ( $n=50,424)$} \\
\hline Secondary and above & $2587(60.3 \%)$ & $31,743(68.8 \%)$ & $34,330(68.1 \%)$ & $<0.001$ & Ref \\
\hline Illiterate & $352(8.2 \%)$ & $2186(4.7 \%)$ & $2538(5.0 \%)$ & $<0.001$ & $1.98(1.75-2.23)$ \\
\hline Literate & $572(13.3 \%)$ & $4763(10.3 \%)$ & $5335(10.6 \%)$ & $<0.001$ & $1.47(1.34-1.62)$ \\
\hline Basic education & $776(18.1 \%)$ & $7445(16.1 \%)$ & $8221(16.3 \%)$ & $<0.001$ & $1.28(1.18-1.39)$ \\
\hline \multicolumn{6}{|l|}{ Smoking $(n=50,422)$} \\
\hline No & $3664(85.5 \%)$ & $41,071(89.0 \%)$ & $44,735(88.7 \%)$ & & Ref \\
\hline Yes & $622(14.5 \%)$ & 5065 (11.0\%) & $5687(11.3 \%)$ & $<0.001$ & $1.38(1.26-1.51)$ \\
\hline \multicolumn{6}{|l|}{ Type of fuel $(n=50,209)$} \\
\hline Clean & 2886 (67.6\%) & 34,628 (75.4\%) & $37,514(74.7 \%)$ & & Ref \\
\hline Polluted & 1384 (32.4\%) & $11,311(24.6 \%)$ & 12,695 (25.3\%) & $<0.001$ & $1.47(1.37-1.57)$ \\
\hline \multicolumn{6}{|l|}{ Sex of the baby } \\
\hline Boy & 2962 (49.7\%) & $29,788(54.4 \%)$ & 32,570 (53.9\%) & & Ref \\
\hline Girl & 3002 (50.3\%) & $24,990(45.6 \%)$ & $27,992(46.1 \%)$ & $<0.001$ & $1.21(1.15-1.27)$ \\
\hline \multicolumn{6}{|l|}{ Multiple delivery } \\
\hline No & $5786(97.0 \%)$ & $54,576(99.6 \%)$ & $60,362(99.4 \%)$ & & Ref \\
\hline Yes & $178(3.0 \%)$ & $202(0.4 \%)$ & $380(0.6 \%)$ & $<0.001$ & $8.31(6.78-10.19)$ \\
\hline \multicolumn{6}{|l|}{ Parity } \\
\hline Multipara & $1084(18.2 \%)$ & 9325 (17.0\%) & 10,409 (17.1\%) & $<0.001$ & Ref \\
\hline Nullipara & 3168 (53.1\%) & $26,647(48.6 \%)$ & 29,815 (49.1\%) & 0.55 & $1.02(0.95-1.10)$ \\
\hline Primipara & $1712(28.7 \%)$ & $18,806(34.3 \%)$ & $20,518(33.8 \%)$ & $<0.001$ & $0.78(0.72-0.85)$ \\
\hline \multicolumn{6}{|c|}{ ANC visit during pregnancy ( $n=49,898)$} \\
\hline$<4$ visits & $1362(32.2 \%)$ & $10,199(22.3 \%)$ & $11,561(23.2 \%)$ & $<0.001$ & $1.65(1.54-1.77)$ \\
\hline$\geq 4$ visits & $2867(67.8 \%)$ & $35,470(77.7 \%)$ & $38,337(76.8 \%)$ & & Ref \\
\hline \multicolumn{6}{|c|}{ Time of first ANC visit $(n=49,898)$} \\
\hline First trimester & $1537(36.3 \%)$ & $19,316(42.3 \%)$ & $20,853(41.8 \%)$ & $<0.001$ & Ref \\
\hline Second trimester & $1818(43.0 \%)$ & $19,105(41.8 \%)$ & $20,923(41.9 \%)$ & $<0.001$ & $1.20(1.11-1.28)$ \\
\hline Third trimester & $874(20.7 \%)$ & $7248(15.9 \%)$ & $8122(16.3 \%)$ & $<0.001$ & $1.52(1.39-1.65)$ \\
\hline \multicolumn{6}{|l|}{ Major malformation } \\
\hline No & $5953(99.8 \%)$ & $54,742(99.9 \%)$ & $60,695(99.9 \%)$ & & Ref \\
\hline Yes & $11(0.2 \%)$ & $36(0.1 \%)$ & $47(0.1 \%)$ & 0.003 & $2.81(1.43-5.52)$ \\
\hline \multicolumn{6}{|c|}{ Severe anaemia during pregnancy } \\
\hline No & $5915(99.2 \%)$ & $54,642(99.8 \%)$ & $60,557(99.7 \%)$ & & Ref \\
\hline Yes & $49(0.8 \%)$ & $136(0.2 \%)$ & $185(0.3 \%)$ & $<0.001$ & $3.33(2.40-4.62)$ \\
\hline \multicolumn{6}{|l|}{ Outcome ( $n=60,062$ ) } \\
\hline Pre-discharge mortality & $460(50.1 \%)$ & 459 (49.9\%) & $919(1.5 \%)$ & $<0.001$ & $10.60(9.28-12.10)$ \\
\hline
\end{tabular}

The risk of preterm births was also higher among women who had severe anemia during pregnancy. The finding is corroborated by other studies which showed severe anemia increased the risk of preterm births significantly [42-45]. Further, mothers who had multiple deliveries had a higher risk of having preterm births. A 
Table 2 Multivariate analysis of factors associated with preterm birth $(n=49,898)$

\begin{tabular}{|c|c|c|c|}
\hline Variables & $\beta$ - coefficient & $p$-value & aOR $(95 \% \mathrm{Cl})$ \\
\hline \multicolumn{4}{|l|}{ Age of mother } \\
\hline $20-<35$ years & Ref & & \\
\hline$<20$ years & 0.234 & $<0.001$ & $1.26(1.15-1.39)$ \\
\hline$>35$ years & 0.180 & 0.082 & $1.20(0.98-1.47)$ \\
\hline \multicolumn{4}{|l|}{ Education level of mother } \\
\hline Secondary and higher & Ref & & \\
\hline Illiterate & 0.346 & $<0.001$ & $1.41(1.22-1.64)$ \\
\hline Literate & 0.186 & 0.001 & $1.21(1.08-1.35)$ \\
\hline Basic education & 0.152 & 0.001 & $1.17(1.07-1.27)$ \\
\hline \multicolumn{4}{|l|}{ Parity of mother } \\
\hline Multipara & Ref & & \\
\hline Nullipara & 0.285 & $<0.001$ & $1.33(1.20-1.48)$ \\
\hline Primipara & -0.013 & 0.812 & $0.99(0.89-1.20)$ \\
\hline \multicolumn{4}{|l|}{ Time of first ANC visit } \\
\hline First trimester & Ref & & \\
\hline Second trimester & 0.125 & 0.001 & $1.13(1.05-1.22)$ \\
\hline Third trimester & 0.218 & $<0.001$ & $1.24(1.12-1.38)$ \\
\hline \multicolumn{4}{|c|}{ ANC visits during pregnancy } \\
\hline$\geq 4$ visits & Ref & & \\
\hline$<4$ visits & 0.398 & $<0.001$ & $1.49(1.38-1.61)$ \\
\hline \multicolumn{4}{|l|}{ Smoking } \\
\hline No & Ref & & \\
\hline Yes & 0.121 & 0.035 & $1.13(1.01-1.26)$ \\
\hline \multicolumn{4}{|l|}{ Type fuel } \\
\hline Clean & Ref & & \\
\hline Polluted & 0.230 & $<0.001$ & $1.26(1.17-1.35)$ \\
\hline \multicolumn{4}{|l|}{ Severe anaemia } \\
\hline No & Ref & & \\
\hline Yes & 1.185 & $<0.001$ & $3.27(2.21-4.84)$ \\
\hline \multicolumn{4}{|l|}{ Multiple delivery } \\
\hline No & Ref & & \\
\hline Yes & 1.891 & $<0.001$ & $6.63(5.16-8.52)$ \\
\hline \multicolumn{4}{|l|}{ Sex of the baby } \\
\hline Boy & Ref & & \\
\hline Girl & 0.164 & $<0.001$ & $1.18(1.11-1.26)$ \\
\hline \multicolumn{4}{|l|}{ Major malformation } \\
\hline No & Ref & & \\
\hline Yes & 0.644 & 0.171 & $1.90(0.76-4.78)$ \\
\hline
\end{tabular}

Korean study [46] and a cohort study in Bangladesh also showed similar findings [20]. However, a systematic review and meta-analyses assessing interventions aimed at preventing preterm births among twin pregnancies found that no interventions reduced the risk significantly [47].
The risk was also higher among women whose babies had major malformations although the association was not significant. However, previous studies have shown significant associations $[48,49]$. One of the reasons could be the low numbers reported from our study. Sex of the child was associated risk with preterm births. 
Several studies have linked male babies to be at higher risk for preterm births [50]. However, a study showed no significant association between sex of the child and preterm births [51-53].

We also analyzed the consequences of preterm birth. Pre-discharge mortality was 11 times higher for preterm babies. Other studies have also reported similar findings $[24,54,55]$.

There are some limitations in the study. The study did not analyze some of the risk factors (e.g. previous medical history, previous preterm births, cervical length, BMI etc.,) that have been discussed in the research articles as these data were either not collected in our study or they were underreported. Another limitation was that not all mothers took part in the interviews and for those who took part, the information might subject to recall bias. Further, we only analyzed pre-discharge mortality and therefore this study does not consider long term consequences. We did not collect data on other outcomes like birth-related injuries and other associated factors hence they are not reported in our study. One strength of this study is its' large representative sample from 12 different hospitals. Hence, the results are a likely representation of the incidence of preterm births in Nepal.

\section{Conclusion}

This study found that factors such as age of mother, literacy levels, smoking habits, delay in seeking ANC services, use of polluted fuel, multiple deliveries and severe anemia can provide as a risk factor for preterm birth.

The incidence of preterm in Nepal remains high. Based on the risk factors linked to preterm identified by this study, implementation of interventions focusing on improving women's literacy, providing better access to clean fuel options, and improving lifestyle, may serve as a protective factor for preterm birth.

Further, improving access to ANC services allowing for better identification of complications, informed choices and safe delivery services can help in reducing risks and consequences associated with preterm births.

\section{Supplementary information}

Supplementary information accompanies this paper at https://doi.org/10 1186/s13690-020-00446-7.

Additional file 1.

Additional file 2 .

\section{Abbreviations}

LMICs: Low- and middle-income countries; ANC: Antenatal care; CSPro: Census and Survey Processing System; SPSS: Statistical Package for the Social Sciences

\section{Acknowledgements}

The authors would like to acknowledge the data collectors and Omkar Basnet at Golden Community.

\section{Authors' contributions}

AKC, AG, PP and AKS conceived and planned the study. AG and AKS performed the analysis. AG prepared the first draft of the manuscript. RG, JW $N R, Y N B, A P, A K S$ and AK reviewed the manuscript. All authors read and approved the final manuscript.

\section{Funding}

No any funding was received for this paper. The study was funded by Einhorn Foundation, Swedish Foundation for International Cooperation in Research and Higher Education (STINT), Swedish Research Council (VR), Laerdal Foundation for Acute Medicine, Norway and UNICEF Nepal country office. Open access funding provided by Uppsala University

\section{Availability of data and materials}

The datasets analyzed for this study will be made available by the corresponding author upon request. Data collection forms (data extraction and exit interview) are provided along with the manuscript as Additional files 1 and 2 .

\section{Ethics approval and consent to participate}

Written informed consent were taken from the mothers before the interview and confidentiality on the information was maintained. The study was approved by Ethical Review Board of Nepal Health Research Council (reference number 26-2017).

\section{Consent for publication}

Consent was taken from the individuals prior to the data collection. The information was coded prior to analysis for anonymity. All records have been kept confidentially, following strict ethical guidelines.

\section{Competing interests}

The authors declare that they have no any competing interests.

\section{Author details}

${ }^{1}$ Golden Community, Lalitpur, Nepal. ${ }^{2}$ Department of Women's and Children's Health, Uppsala University, 75237 Uppsala, Sweden. ${ }^{3}$ Lumbini Provincial Hospital, Government of Nepal, Butwal, Nepal. "Bharatpur Hospital, Government of Nepal, Chitwan, Nepal. ${ }^{5}$ Ministry of Health and Population, Government of Nepal, Kathmandu, Nepal. 'Syangya District Hospital, Government of Nepal, Syangya, Nepal.

Received: 23 January 2020 Accepted: 3 July 2020

Published online: 17 July 2020

References

1. Blencowe $H$, Cousens S, Oestergaard MZ, Chou D, Moller AB, Narwal R, et al. National, regional, and worldwide estimates of preterm birth rates in the year 2010 with time trends since 1990 for selected countries: a systematic analysis and implications. Lancet. 2012;379(9832):2162-72.

2. Liu L, Oza S, Hogan D, Chu Y, Perin J, Zhu J, et al. Global, regional, and national causes of under-5 mortality in 2000-15: an updated systematic analysis with implications for the sustainable development goals. Lancet. 2016:388(10063):3027-35.

3. Every Preemie - SCALE. Nepal profile of preterm and low birth weight prevention and care. 2014. Available from: http://www. healthynewbornnetwork.org/hnn-content/uploads/Kenya-1.pdf\%0Ahttp:// www.everypreemie.org/.

4. Lee ACC, Katz J, Blencowe H, Cousens S, Kozuki N, Vogel JP, et al. National and regional estimates of term and preterm babies born small for gestational age in 138 low-income and middle-income countries in 2010. Lancet Glob Health. 2013;1:e26-36.

5. Beck S, Wojdyla D, Say L, Betran AP, Merialdi M, Requejo JH, et al. The worldwide incidence of preterm birth: a systematic review of maternal mortality and morbidity. Bull World Health Organ. 2010;88(1):31-8.

6. United Nations Development Programme. SDG 3 ensure healthy lives and promote well- being for all at. Undp support to implement sustain dev goal 3, vol. 2017; 2017. p. 1-20. Available from: http://www.undp.org/content/ 
undp/en/home/librarypage/sustainable-development-goals/undp-supportto-the-implementation-of-the-2030-agenda.html.

7. Katz J, Lee ACC, Kozuki N, Lawn JE, Cousens S, Blencowe H, et al. Mortality risk in preterm and small-for-gestational-age infants in low-income and middle-income countries: a pooled country analysis. Lancet. 2013;382(9890): 417-25.

8. Lawn JE, Cousens S, Zupan J. 4 Million neonatal deaths: When? Where? Why? Lancet. 2005;365:891-900.

9. Christian P, Murray-Kolb LE, Tielsch JM, Katz J, LeClerq SC, Khatry SK. Associations between preterm birth, small-for-gestational age, and neonatal morbidity and cognitive function among school-age children in Nepal. BMC Pediatr. 2014;14(1):58.

10. Blencowe H, Cousens S, Chou D, Oestergaard M, Say L, Moller A-B, et al. Born too soon: the global epidemiology of 15 million preterm births. Reprod Health. 2013:10(Suppl 1):S2.

11. Kildea SV, Gao Y, Rolfe M, Boyle J, Tracy S, Barclay LM. Risk factors for preterm, low birthweight and small for gestational age births among Aboriginal women from remote communities in northern Australia. Women Birth. 2017;30(5):398-405.

12. Savitz DA, Murnane P. Behavioral influences on preterm birth: A review. Epidemiology. 2010:21:291-9.

13. Auger N, Leduc L, Naimi Al, Fraser WD. Delivery at term: impact of university education by week of gestation. J Obstet Gynaecol Canada. 2016;38(2):118-24.

14. Oftedal AM, Busterud K, Irgens LM, Haug K, Rasmussen S. Socio-economic risk factors for preterm birth in Norway 1999-2009. Scand J Public Health. 2016;44(6):587-92.

15. Poulsen G, Strandberg-Larsen K, Mortensen L, Barros H, Cordier S, Correia S, et al. Exploring educational disparities in risk of preterm delivery: a comparative study of 12 European birth cohorts. Paediatr Perinat Epidemiol. 2015;29(3):172-83

16. Delnord $\mathrm{M}$, Blondel $\mathrm{B}$, Prunet $\mathrm{C}$, Zeitlin J. Are risk factors for preterm and early-term live singleton birth the same? A population-based study in France. BMJ Open. 2018;8(1):e018745.

17. Shrestha S, Dangol Singh S, Shrestha M, Shrestha RP. Outcome of preterm babies and associated risk factors in a hospital. J Nepal Med Assoc. 2010; 50(4):286-90.

18. Goldenberg RL, Culhane JF, lams JD, Romero R. Epidemiology and causes of preterm birth. Lancet. 2008:371:75-84.

19. Daltveit AK, Vollset SE, Skjærven R, Irgens LM. Impact of multiple births and elective deliveries on the trends in low birth weight in Norway, 1967-1995. Am J Epidemiol. 1999;149(12):1128-33.

20. Shah R, Mullany LC, Darmstadt GL, Mannan I, Rahman SM, Talukder RR, et al. Incidence and risk factors of preterm birth in a rural Bangladeshi cohort. BMC Pediatr. 2014;14(1):112.

21. Ashish KC, Bergström A, Chaulagain D, Brunell O, Ewald U, Gurung A, et al. Scaling up quality improvement intervention for perinatal care in Nepal (NePeriQIP); Study protocol of a cluster randomised trial. BMJ Glob Health. 2017:2(3):e000497.

22. Chawanpaiboon S, Vogel JP, Moller AB, Lumbiganon P, Petzold M, Hogan D, et al. Global, regional, and national estimates of levels of preterm birth in 2014: a systematic review and modelling analysis. Lancet Glob Health. 2019; 7(1):e37-46.

23. Purisch SE, Gyamfi-Bannerman C. Epidemiology of preterm birth. Semin Perinatol. 2017;41:387-91.

24. Kc A, Wrammert J, Nelin V, Ewald U, Clark R, Målqvist M. Level of mortality risk for babies born preterm or with a small weight for gestation in a tertiary hospital of Nepal. BMC Public Health. 2015;15(1):877.

25. Anderson C, Smitherman AB, Engel SM, Nichols HB. Modifiable and nonmodifiable risk factors for preterm delivery among adolescent and young adult cancer survivors. Cancer Causes Control. 2018;29(2):289-95.

26. Leonard SA, Crespi CM, Gee DC, Zhu Y, Whaley SE. Prepregnancy risk factors for preterm birth and the role of maternal nativity in a low-income, Hispanic Population. Matern Child Health J. 2015;19(10):2295-302.

27. Muhihi A, Sudfeld CR, Smith ER, Noor RA, Mshamu S, Briegleb C, et al. Risk factors for small-for-gestational-age and preterm births among 19,269 Tanzanian newborns. BMC Pregnancy Childbirth. 2016;16(1):110.

28. Weng YH, Yang CY, Chiu YW. Risk assessment of adverse birth outcomes in relation to maternal age. PLoS One. 2014;9(12):e114843.

29. Fuchs $F$, Monet B, Ducruet $T$, Chaillet $N$, Audibert F. Effect of maternal age on the risk of preterm birth: A large cohort study. Obstet Gynecol Survey. 2018;73:340-2.
30. Wagura P, Wasunna A, Laving A, Wamalwa D, Ng'ang'a P. Prevalence and factors associated with preterm birth at kenyatta national hospital. BMC Pregnancy Childbirth. 2018;18(1):107.

31. Heaman M, Kingston D, Chalmers B, Sauve R, Lee L, Young D. Risk factors for preterm birth and small-for-gestational-age births among Canadian women. Paediatr Perinat Epidemiol. 2013;27(1):54-61.

32. Wallace $\mathrm{LL}$, Aland KL, Blatt K, Moore E, DeFranco EA. Modifying the risk of recurrent preterm birth: influence of trimester-specific changes in smoking behaviors. Am J Obstet Gynecol. 2017;216(3):310.e1-8.

33. Meertens LE, van Montfort P, Scheepers HCJ, van Kuijk SMJ, Aardenburg R, Langenveld J, et al. Prediction models for the risk of spontaneous preterm birth based on maternal characteristics: a systematic review and independent external validation. Acta Obstetricia et Gynecologica Scandinavica. 2018;97:907-20.

34. Koullali B, Oudijk MA, Nijman TAJ, Mol BWJ, Pajkrt E. Risk assessment and management to prevent preterm birth. Semin Fetal Neonatal Med. 2016;21:80-8.

35. Liu W, Huang C, Cai J, Wang X, Zou Z, Sun C. Household environmental exposures during gestation and birth outcomes: a cross-sectional study in Shanghai, China. Sci Total Environ. 2018;615:1110-8.

36. Wylie BJ, Coull BA, Hamer DH, Singh MP, Jack D, Yeboah-Antwi K, et al. Impact of biomass fuels on pregnancy outcomes in central East India. Environ Health. 2014;13:1.

37. Salihu H, Mbah AK, Alio AP, Kornosky JL, Whiteman VE, Belogolovkin V, et al. Nulliparity and preterm birth in the era of obesity epidemic. J Matern Neonatal Med. 2010;23(12):1444-50.

38. Mayo JA, Shachar BZ, Stevenson DK, Shaw GM. Nulliparous teenagers and preterm birth in California. J Perinatal Med. 2017;45:959-67.

39. Beeckman K, Louckx F, Downe S, Putman K. The relationship between antenatal care and preterm birth: the importance of content of care. Eur $J$ Pub Health. 2013;23(3):366-71.

40. Jammeh A, Sundby J, Vangen S. Maternal and obstetric risk factors for low birth weight and preterm birth in rural Gambia: a hospital-based study of 1579 deliveries. Open J Obstet Gynecol. 2011;01(03):94-103.

41. Requejo J, Merialdi M, Althabe F, Keller M, Katz J, Menon R. Born Too Soon: Care during pregnancy and childbirth to reduce preterm deliveries and improve health outcomes of the preterm baby. Reprod Health. 2013;10:54.

42. Bondevik GT, Lie RT, Ulstein M, Kvale G. Maternal hematological status and risk of low birth weight and preterm delivery in Nepal. Acta Obstet Gynecol Scand. 2001;80(5):402-8.

43. Yi SW, Han YJ, Ohrr H. Anemia before pregnancy and risk of preterm birth, low birth weight and small-for-gestational-age birth in Korean women. Eur . Clin Nutr. 2013;67(4):337-42.

44. Parks S, Hoffman MK, Goudar SS, Patel A, Saleem S, Ali SA, et al. Maternal anaemia and maternal, fetal, and neonatal outcomes in a prospective cohort study in India and Pakistan. BJOG. 2019;126(6):737-43.

45. Stephen G, Mgongo M, Hussein Hashim T, Katanga J, Stray-Pedersen B, Msuya SE. Anaemia in pregnancy: prevalence, risk factors, and adverse perinatal outcomes in northern Tanzania. Anemia. 2018;2018:1846280.

46. Kim J-I, Cho M-O, Choi G-Y. Multiple factors in the second trimester of pregnancy on preterm labor symptoms and preterm birth. J Korean Acad Nurs. 2017:47:357-66.

47. Jarde A, Lutsiv O, Park CK, Barrett J, Beyene J, Saito S, et al. Preterm birth prevention in twin pregnancies with progesterone, pessary, or cerclage: a systematic review and meta-analysis. BJOG. 2017;124:1163-73.

48. Purisch SE, DeFranco EA, Muglia LJ, Odibo AO, Stamilio DM. Preterm birth in pregnancies complicated by major congenital malformations: a populationbased study. Am J Obstet Gynecol. 2008;199(3):287.e1-8.

49. Honein MA, Kirby RS, Meyer RE, Xing J, Skerrette NI, Yuskiv N, et al. The association between major birth defects and preterm birth. Matern Child Health J. 2009:13(2):164-75.

50. Lao TT, Sahota DS, Suen SSH, Law LW. The impact of fetal gender on preterm birth in a southern Chinese population. J Matern Neonatal Med. 2011;24(12):1440-3.

51. Peelen MJCS, Kazemier BM, Ravelli ACJ, De Groot CJM, Van Der Post JAM, Mol BWJ, et al. Impact of fetal gender on the risk of preterm birth, a national cohort study. Acta Obstet Gynecol Scand. 2016;95(9):1034-41.

52. Astolfi P, Zonta LA. Risks of preterm delivery and association with maternal age, birth order, and fetal gender. Hum Reprod. 1999;14(11):2891-4.

53. Teoh PJ, Ridout A, Seed P, Tribe RM, Shennan AH. Gender and preterm birth: is male fetal gender a clinically important risk factor for preterm birth in high-risk women? Eur J Obstet Gynecol Reprod Biol. 2018;225:155-9. 
54. Sania A, Smith ER, Manji K, Duggan C, Masanja H, Kisenge R, et al. Neonatal and infant mortality risk associated with preterm and small for gestational age births in tanzania: individual level pooled analysis using the intergrowth standard. J Pediatr. 2018;192:66-72.e4.

55. Draper ES, Manktelow BN, Cuttini M, Maier RF, Fenton AC, Van Reempts P, et al. Variability in very preterm stillbirth and in-hospital mortality across Europe. Pediatrics. 2017;139(4):e20161990.

\section{Publisher's Note}

Springer Nature remains neutral with regard to jurisdictional claims in published maps and institutional affiliations.

Ready to submit your research? Choose BMC and benefit from:

- fast, convenient online submission

- thorough peer review by experienced researchers in your field

- rapid publication on acceptance

- support for research data, including large and complex data types

- gold Open Access which fosters wider collaboration and increased citations

- maximum visibility for your research: over $100 \mathrm{M}$ website views per year

At $\mathrm{BMC}$, research is always in progress.

Learn more biomedcentral.com/submissions 